\title{
La recepción extraacadémica de Michel Foucault en la cultura de la Transición española: la antipsiquiatría y la Historia de la locura en los psiquiatras progresistas.
}

\author{
Michel Foucault's extra-academic reception in the culture \\ of the Spanish transition: the antipsychiatry and the Histoire \\ de la folie in the progressive psychiatrists.
}

\begin{abstract}
RESUMEN: El artículo es una aportación a la recepción extraacadémica del pensamiento de Michel Foucault, referida a la lucha psiquiátrica. Hemos realizado un recorrido por los primeros textos antiinstitucionales y antipsiquiátricos, que se leyeron en España en estrecha relación con parte de la obra foucaultiana, y en particular analizamos el interés y la influencia que despertó la Historia de la locura entre los psiquiatras progresistas españoles.

PALABRAS CLAVE: Recepción extraacadémica, antipsiquiatría, Foucault, Historia de la locura, psiquiatras progresistas.
\end{abstract}

\begin{abstract}
This article contributes to the extra-academic reception of Michel Foucault's thought, referring to the psychiatric fight. The first antiinstitutional and antipsychiatric texts have been looked through, those which were read in Spain and were closely related to a part of Foucault's work, the interest and influence risen by Histoire de la folie among Spanish progressive psychiatrists have been particulary analysed.

KEY WORDS: Extra-academic reception, antipsychiatry, Foucault, Histoire de la folie, progressive psychiatrists.
\end{abstract}

Durante los últimos años del franquismo y los primeros años de la Transición encontramos la existencia de una teoría y un debate antiinstitucional sobre la ciencia psiquiátrica, a veces ambigua con respecto a algunos textos de Michel Foucault, especialmente en el caso de la lectura libertaria del psiquiatra Ramón García. Estas imprecisiones son más comprensibles en publicaciones, en mayor o menor grado alternativas, como Ajoblanco o El Viejo Topo, que justificamos por el propio enfoque de Enfermedad mental y personalidad y por la proximidad del filósofo francés a la llamada psiquiatría crítica o antipsiquiatría, como podemos constatar en algún curso del Colegio de Francia, en la participación de la obra colectiva Los crímenes de la paz, o en el prólogo a la edición inglesa de El AntiEdipo.

De manera paralela coexistieron luchas concretas, por parte de los psiquiatras progresistas y de los propios pacientes, que contribuyeron al conocimiento y toma de conciencia de esta problemática como una forma más de violencia social. Por ello, nos hemos aproximado a los usos y distorsiones que hicieron algunos psiquiatras de la obra foucaultiana, básicamente de Historia de la locura, 
para adaptarla a sus intereses y objetivos, dentro de las pugnas que conformaron el campo intelectual español. Lectura dirimida entre lo académico de sus congresos y la recepción extraacadémica, puesta de manifiesta en la batalla cotidiana de los internados.

Los movimientos de detracción a la psiquiatría clásica no nacieron hasta la década de los años 60. Las reflexiones comunes de sociólogos, filósofos, políticos, psiquiatras y enfermos mentales coincidieron en un severo replanteamiento del saber psiquiátrico y de las prácticas propugnadas. En 1967 David Cooper ${ }^{\mathrm{I}}$ propuso el término antipsiquiatría, convirtiéndose en el estandarte de estos nuevos planteamientos, si bien él mismo se sorprendió de la desmedida popularización del neologismo: el vocablo antipsiquiatría no encierra un conjunto doctrinal ni un tipo de praxis estandarizadas, sino una serie de posturas críticas que sólo adquieren sentido en su particular contexto ${ }^{I I}$. Con anterioridad al movimiento psiquiátrico se publicaron dos textos fundamentales, nos referimos a Internados. Ensayos sobre la situación social de los enfermos mentales de Erving Goffman ${ }^{\mathrm{III}}$, y a la Historia de la locura en la época clásica $^{I V}$. Ambas obras publicadas en 1961 y conocidas, hasta entonces, exclusivamente en el ámbito académico.

Resulta significativo el silencio con que fue acogida la Tesis Doctoral de Michel Foucault, ya que antes de 1966 no encontramos ninguna reacción en las publicaciones de la izquierda francesa, lo cual indica que sus enfoques y problemáticas tuvieron escasa repercusión hasta los acontecimientos de Mayo del 68 , los cuales propiciaron unas condiciones más favorables para su discurso: lo que yo había intentado hacer en este campo (se refiere a Historia de la locura) ha sido recibido con un gran silencio en la izquierda intelectual francesa. Y solamente alrededor del 68, superando la tradición marxista y pese al Partido Comunista, todas estas cuestiones han adquirido su significación política, con una intensidad que no había sospechado y que mostraba bien en qué medida mis anteriores libros eran todavía tímidos y confusos. Sin la apertura política realizada estos mismos años no habría tenido sin duda el valor de retomar el

I Cooper, D., Psiquiatría y Antipsiquiatría, Buenos Aires, Paidós, 1978, 4ª edición. (Traducción de Jorge Piatigorsky).

II Citado por Fábregas, J. L.; Mora, E.; RoIG, A., "Por una psiquiatría alternativa", El Viejo Topo, 1977, nº 15, Diciembre, PP. 18-23, P. 19.

III Goffman, E., Internados. Ensayos sobre la situación social de los enfermos mentales, Madrid, Martínez de Murguía, 1970. (Traducción de María Antonia Oyuela de Grant).

IV Existen tres ediciones de la obra Folie et Déraison. Histoire de la folie à l'âge classique, (1961), París, Plon. Ésta fue reimpresa en: a) 1964, Union Générale d'Editions, versión abreviada; b) 1972, Gallimard, versión original. En esta edición se suprimen los dos primeros términos del título original, y aparece con tres trabajos nuevos: un Prefacio y dos Apéndices: "La folie, l'absence d'oeuvre" y "Mon corps, ce papier, ce feu"; y c) 1978, de nuevo en Gallimard, sin los apéndices anteriores. En castellano, Historia de la locura en la época clásica, (1967), Méjico, Fondo de Cultura Económica, a partir de la edición de Plon. Con los textos incorporados en Gallimard, (1972), en la 2a edición de FCE, 1976. (Traducción de Juan José Utrilla). 
ORIGINALES Y REVISIONES

hilo de estos problemas y seguir mi investigación del lado de la penalidad, de las prisiones, de las disciplinas ${ }^{V}$.

La influencia efectiva de Mayo del 68 se hizo notar en la trayectoria política de Foucault, probablemente como descubrimiento de su auditorio contestatario, como los locos y los manicomios, los marginados y las cárceles, los inmigrantes y las fábricas, los objetores de conciencia y los cuarteles, los estudiantes y la disciplina, etc. Sin duda que encontró integrados en estos movimientos muchos de los problemas que anteriormente se había dedicado a investigar y que con el Mayo del 68 recibieron un estatuto político. Un ejemplo importante: la contestación psiquiátrica ${ }^{V I}$. Diez años después del movimiento de Mayo, los periodistas Santi Soler y Rossend Arqués, colaboradores de Ajoblanco, viajaron a París para entrevistar a Foucaultl En el diálogo recordaba el filósofo de Poitiers que la Historia de la locura fue relegada por el ostracismo de los marxistas de los años 60 y absolutamente incomprendida por los anarquistas. Asimismo lamentaba como su obra fue a parar a manos de policías y funcionarios de prisiones, quienes la estudiaron en vano pensando que encontrarían sugerencias para perfeccionar los sistemas de represión y sus abusos de poder ${ }^{V I I}$.

Las investigaciones de Goffman y Foucault sobre las dos grandes instituciones cerradas, el manicomio y la cárcel, además de las influencias del Mayo francés, fueron también divulgadas por el movimiento de la psiquiatría antiinstitucional. En concreto, Internados se publicó en Italia por los Basaglia (padre e hija) y en Francia por Robert Castel, mientras que la traducción inglesa de Madnes and Civilization se editó en la colección dirigida por Ronald Laing, con prólogo de David Cooper. Próximo a la problemática antipsiquiátrica, Michel Foucault impartió en el Colegio de Francia los seminarios "El poder psiquiátrico"VIII y "Los anormales"'x , y colaboró en la publicación conjunta Los crímenes de la

v Foucault, M., "Verdad y poder" en, Microfísica del poder, Madrid, La Piqueta, 1978, PP. 175-189, P. 177. (Traducción de Julia Varela y Fernando Álvarez-Uría). Texto original, "Vérité et pouvoir" (Entrevista de A. Fontana en Junio de 1976) en, PASQUINO, P.; FONTANA, A., Michel Foucault. Microfísica del potere. Interventi politici, Turín, Einaudi, 1977, PP. 3-28. Versión abreviada en, L'arc, nº 70, especial, 1977, PP. 16-26.

vi Morey, M., "Introducción a Michel Foucault" en, Sexo, Poder, Verdad. Conversaciones con Michel Foucault, Barcelona, Materiales, 1978, PP. 9-65, P. 48.

VII Soler, S.; ArquÉs, R., "Entrevista a Michel Foucault", Ajoblanco, 1978, no 31, Marzo, PP. 13-15. Sobre la publicación Ajoblanco véase, RIBAS, J., Los 70 a destajo. Ajoblanco y libertad, Barcelona, RBA, 2007.

VIII Foucault, M., (Resumen del curso 1973-1974), "Le pouvoir psychiatrique". Un resumen de "El poder psiquiátrico" se publicó en castellano como "Psiquiatría y Antipsiquiatría" en, FOUCAULT, M., La vida de los hombres infames. Ensayos sobre desviación y dominación, Madrid, La Piqueta, 1990, PP. 69-82. (Traducción de Julia Varela y Fernando Álvarez-Uría). Para consultar el texto completo véase, FOUCAULT, M., El poder psiquiátrico, Madrid, Akal, 2005.

IX Foucault, M., (Resumen del curso 1974-1975), "Les anormaux". Véase "Los anormales" en, FOUCAULT, M., La vida de los hombres infames. Ensayos sobre desviación y dominación, opus cit., (1990), PP. 83- 91. También en FOUCAULT, M., Hay que defender la sociedad, Buenos Aires, Almagesto, 1992, PP. 9-17. (Traducción de Jorge Fernández Vega). 
paz, con el artículo "La casa de la locura"x. Estos textos coincidieron, desde la perspectiva antinormativa, en denunciar la violencia institucional, en tanto que no habían recibido el suficiente impulso social y político: el problema de los controles sociales -al cual estaban ligadas todas las cuestiones relativas a la locura, la medicina, la psiquiatría- no apareció en el gran forum más que después de Mayo del $68^{X I}$.

La revuelta estudiantil selló un encuentro sin precedentes entre la Historia de la locura que nadie leyó hasta 1968, incluidos los médicos psiquiatras, y El Anti-Edipo. Capitalismo y esquizofrenia, obra de Gilles Deleuze y del psiquiatra en ruptura con el psicoanálisis, Félix Guattari. El ensayo suscitó comentarios, pasiones e incomprensiones que desbordaron el círculo de los especialistas por presentarse aparentemente como un efecto de Mayo del 68, y como un hecho cultural donde el psicoanálisis, quizás por primera vez se percibía derrotado: la sociedad de las barricadas es la irrupción del futuro en el presente. Esa noche (se refiere al viernes, 10 de Mayo de 1968), cuando los estudiantes sitiaron la Sorbona, dejó en paro forzoso a un gran número de psicoanalistas. Miles de personas sintieron el deseo de hablarse y amarse ${ }^{X I I}$.

En El Anti-Edipo se propone un análisis político y social del deseo que, como la locura, no se podía separar de la historia, de la sociedad ni de sus coacciones. Deleuze y Guattari arremetieron contra la conservadora psiquiatría oficial, preocupada por la función de readaptación del individuo al sistema represivo, enfrentándose al psicoanálisis por su simplista e inútil repetición: Edipo, castración, mamá y papá. Para los autores de El Anti-Edipo ${ }^{X I I I}$, el filósofo francés había demostrado que el familiarismo inherente al psicoanálisis coronaba la psiquiatría clásica. La pretensión que organizó la psiquiatría del siglo XIX en el asilo, halló su conclusión fuera de él, particularmente en el psicoanálisis y en el despacho del analista, por tanto en vez de participar en una empresa de liberación efectiva, el psicoanálisis se une a la obra de represión burguesa más general, la que consiste en mantener a la humanidad europea bajo el yugo de

x Foucault, M., "La casa de la locura" en, BASAGLIA y otros, Los crímenes de la paz, Méjico, Siglo XXI, 1977, PP. 135-150. (Traducción de Carmen Valcarce).

XI EzINE, J. L., "Sur la sellette: Michel Foucault", (Entrevista con Michel Foucault: "Acerca del banqui1lo"), Les Nouvelles Littéraires, 1975, n² 2477, 17-23 de Marzo, P. 3.

XII Cohn-Bendit, D., “Anniversaire: Cohn-Bendit raconte Mai 68”, Le Nouvel Observateur, n 547, 5 Agosto-1 Mayo, 1975, PP. 71-106, P. 90. Citado por VARELA, J.; ÁLVAREZ-URÍA, F., "Psicoanálisis y control social", Negaciones, 1976, n 2, Diciembre, PP. 151-163, P. 153.

XIII Hasta la edición de El Anti-Edipo, Gilles Deleuze había consagrado su obra a Hume, Spinoza, Nietzsche y Kant. Por su parte, Félix Guattari -psiquiatra y psicoanalista- procedente de la escuela lacaniana, mantuvo su compromiso en diferentes movimientos de izquierda. En principio, dentro del trotskismo, después en contacto con la oposición del Partido Comunista Francés, y también con el grupo de intelectuales "22 de Marzo". Este movimiento, anterior al Mayo del 68, publicó una serie de panfletos sobre el rol de la Sociología en el mundo moderno, denunciando la falsa neutralidad de las Ciencias Sociales. 
papá-mamá, <lo que impide acabar con aquél problema $>^{X I V}$. Si El Anti-Edipo supuso un vuelco en los principios institucionales menos discutidos de la práctica psicoanalítica, nos sorprende que en su día fuese más atacada por los pedagogos conductistas que por los propios psicoanalistas. De provocador podemos calificar el juicio demoledor del historiador de la filosofía, François Châtelet, para quien los médicos psiquiatras, que son unos ignorantes en el campo intelectual, se han visto obligados a causa de la presión pública a leer $<$ La Historia de la locura $>$ y luego se han mostrado menos orgullosos que antes. No han podido pretender detentar el saber porque se han dado cuenta de hasta que punto el $<$ saber $>$ es frágil. E igualmente, después del <Anti-Edipo > ha sido un hecho que cierto número de psicoanalistas han salido a la calle rozando las paredes con vergüenza porque les molestaba lo que decían Deleuze y Guattari ${ }^{X V}$. No en balde Foucault escribió el Prefacio de la edición inglesa, titulado "El Anti-edipo: una introducción a la vida no fascista"XVI. Estos análisis y luchas antiinstitucionales adquirieron radicalidad en su intento por desenmascarar los mecanismos de producción de la realidad, bien como producto del poder en el caso de Foucault, o bien como producto del deseo según Deleuze y Guattari en El Anti-Edipo ${ }^{\mathrm{XVII}}$.

En nuestro país el psiquiatra Ramón García ${ }^{\mathrm{XVIII}}$ presentó los primeros textos antipsiquiátricos, prologando la edición española de La institución negada ${ }^{\mathrm{XIX}} \mathrm{y}$ la introducción de ¿Psiquiatría o ideología de la locura? ${ }^{X X}$ Ambos son recopilaciones iniciadas por la familia Basaglia y recogidas por su equipo, en torno a las experiencias psiquiátricas desarrolladas en el Hospital Psiquiátrico de Trieste. En los dos escritos citados aludía su autor a las prácticas de un grupo internacional

xiv Deleuze, G.; Guattari, F., El Anti Edipo. Capitalismo y esquizofrenia, Barcelona, Paidós, 1985, P. 54. (Traducción de Francisco Monge). Edición original en, Barcelona, Barral Editores, 1973.

xv Vicens, A., "Filosofía y desobediencia" (Entrevista a François Châtelet), El Viejo Topo, 1977, n 10, Julio, PP. 39-43, P. 42.

XVI Foucault, M., "Preface" en, Anti-Oedipus: Capitalism and Schzophrenia, Nueva York, Viking Press, 1977. (También en Minneapolis, University of Minnesota Press, 1983). En castellano, "El Antiedipo: una introducción a la vida no fascista”, Archipiélago. Cuadernos de crítica de la cultura, 1994, nº 17, Octubre-Diciembre, PP. 88-91.

XVII Morey, M., “Taller de títeres: de instintos e instituciones”, El Viejo Topo, 1977, nº 6, Marzo, PP. 43-44.

xvIIIRAMÓN García estudió Medicina y Psiquiatría en la Universidad de Zaragoza y Barcelona. Ejerció la docencia como Profesor de Psicología en la Universidad catalana, hasta su despido en 1968 por motivos políticos. Trabajó en el Hospital Mental de la Santa Cruz de Barcelona, del que fue expulsado en 1973, y posteriormente en el Hospital Psiquiátrico de Bétera (Valencia). Fue Miembro Fundador del Colectivo Crítico para la Salud Mental.

XIx García, R.; Serós, A.; Torrent, L., "Una experiencia frente a la ciencia" (Prólogo) en, BASAGLIA, F.; BASAGLIA, F. (compiladores), La institución negada, Barcelona, Barral Editores, 1972, PP. 7-17. (Traducción de Jaime Pomar).

xx GARcía, R., "Ideología de la locura y locuras de la ideología” en, BASAGLIA, F. y otros, ¿Psiquiatría o ideología de la locura?, Barcelona, Anagrama, 1972. (Selección, revisión y notas de Ramón García). Los textos citados, "Una experiencia frente a la ciencia" e "Ideología de la locura y locuras de la ideología" son dos de los seis ensayos publicados en, GARCÍA, R., ;Abajo la autoridad! Ciencia, manicomio y muerte, Barcelona, Anagrama, 1979. 
de psiquiatras, proponiendo para el caso español la urgente participación y comunicación de los Hospitales Psiquiátricos a través de la semiclandestina "Coordinadora Psiquiátrica Nacional". Ésta surgió como un movimiento solidario, en relación con el conflicto laboral del Hospital Psiquiátrico de Oviedo: el hospital psiquiátrico es un centro de régimen custodial o carcelario destinado a $<$ recoger $>$, así se oye cada día, a aquellos que no se adaptan a las normas sociales establecidas y no participan en el proceso de producción (...) Al afirmar el Hospital Psiquiátrico como una institución manipuladora no hacemos más que afirmar lo que hemos vivido a través de nuestra práctica ${ }^{X X I}$. Sin una organización precisa agrupó a algunos psiquiatras progresistas y a los trabajadores más inquietos de los centros psiquiátricos. En sus reivindicaciones denunciaron, básicamente, la exclusión social del enfermo mental, la privación de derechos elementales, el régimen custodial y jerárquico de los manicomios, como también los dudosos y controvertidos diagnósticos clínicos. La Coordinadora Psiquiátrica perdió en la práctica su razón de ser y cayó en un largo letargo, hasta que iniciado el conflicto laboral en el Instituto Mental de la Santa Cruz de Barcelona ${ }^{\mathrm{XXII}}$ volvió a activarse, alcanzando en 1973 su máxima vitalidad. Posteriormente, a mediados de 1975, llegó a su fin celebrándose el último encuentro en Santiago de Compostela, a propósito de otro conflicto, el del Hospital Psiquiátrico de Conxo ${ }^{\mathrm{XXIII}}$.

Desde la Coordinadora Psiquiátrica Nacional, Ramón García -expulsado del Hospital Mental de la Santa Cruz de Barcelona en 1973- discrepó sobre la historia de la psiquiatría institucional. Desde el siglo XIX los hospitales psiquiátricos se habían convertido en un sutil encubrimiento de la violencia necesaria para silenciar la locura, entendiendo que en la historia del manicomio la palabra del psiquiatra conformó el orden, los valores y la moral de la clase burguesa. Con este planteamiento, la supuesta felicidad del loco era la imagen ideal e ideológica de una posible y ficticia libertad, establecida en el interior del espacio manicomial. Este sueño de libertad sólo se producía a condición de que el comportamiento del loco mostrase como sumisos los valores normativos que se le imponían, y que

xxI Escrito de algunos de los ex-trabajadores del Hospital Psiquiátrico de Oviedo despedidos en 1971. Véase El Viejo Topo, 1977, "Sección Antipsiquiatría”, n 4, Enero, PP. 29-40, P. 34.

XXII Todo el proceso que viene desarrollándose en el Instituto Mental no es más que la culminación de una serie de hechos cotidianamente demostrables: la exclusión social -cristalizada en el interior mismo de las estructuras sanitarias- del enfermo mental y, con él, del personal sanitario que a través de la práctica ha hecho suyo el problema del enfermo mental a quien trata. Escrito de los trabajadores del Instituto Mental de la Santa Cruz de Barcelona, despedidos en 1973. Ibidem.

XXIII La institución manicomial priva a los internados de los más elementales derechos, al mismo tiempo esconde y encubre las contradicciones sociales implícitas en la enfermedad (...) La transformación institucional ha de llevar necesariamente el resurgir de esas contradicciones y el ejercicio de aquellos derechos. Escrito de un grupo de ex-trabajadores del Hospital Psiquiátrico de Conxo, en su mayoría despedidos, Santiago de Compostela, 1975. Ibidem. 
ORIGINALES Y REVISIONES

constituían a su vez los valores ideológico-morales de la producción ${ }^{\mathrm{XXIV}}$.

Al igual que los textos antipsiquiátricos, Ramón García había leído Enfermedad mental y personalidad y la Historia de la locura en la época clásica. En estas obras se revela la incomunicación existente entre el hombre razonable y el hombre loco, escisión y violencia acentuadas en la institución manicomial y constatadas en conceptos como diagnóstico, técnica terapéutica, curación, y más nítidamente en el de enfermedad, ya que en esta última noción la psiquiatría estableció como poder clasificatorio la línea divisoria entre lo normal o inclusión y lo patológico o exclusión ${ }^{X X V}$. Con estos antecedentes, el nuevo orden manicomial se reflejaba en el psiquiatra en su papel de excluyente, en la institución como lugar de exclusión, y decisivamente en el enfermo como sujeto excluido. Por tanto, la práctica psiquiátrica consideró al loco y a su locura como un error, que necesariamente había que subsanar para poder ser normalizado: nuestra sociedad no quiere reconocerse en ese enfermo que lleva dentro y lo aparta y lo encierra; en el mismo momento que diagnostica la enfermedad, excluye al enfermo ${ }^{X V I}$. La medicina y la psiquiatría como mediadores del poder establecido no pretendieron confinar a la locura con la única finalidad de excluirla, sino también encerrarla para su tratamiento y organizar la violencia necesaria para dominar, controlar y domesticar al loco. En la Historia de la locura se identifica el manicomio con un espacio judicial donde se acusa, juzga, condena y castiga a la locura, aunque ésta sea inocente en el exterior. El poder del médico-psiquiatra quedó establecido por un contrato social que le hizo garante de la norma y de sus funciones: desde finales del siglo XVIII el certificado médico ha llegado a ser casi obligatorio para internar a los locos en el interior mismo del manicomio, si se exige la profesión médica, es como garantía jurídica y moral, no como título científico ${ }^{X X V I I}$. El proceso de domesticación de la locura nació apoyado por la ideología médica, en una época positivista y burguesa, siendo decisivo para su reconocimiento social el contrato que ligó a la psiquiatría con los poderes políticos.

Aparte del distanciamiento cronológico, de Historia de la locura (1961) y Enfermedad mental y personalidad (1954), Ramón García ignoró que los presupuestos de ambos ensayos son diferentes. En el texto de 1954 la naturaleza de la

\footnotetext{
${ }^{\text {XXIV }}$ GARCíA, R., "Los conflictos psiquiátricos en España: de la renuncia del manicomio a la ruptura con la norma institucional", El Viejo Topo, 1977, nº 4, Enero, PP. 37-39.

${ }^{\mathrm{xxv}}$ GARCíA, R., "Una experiencia frente a la ciencia” en, BASAGLIA, F. y otros, ¿Psiquiatría o ideología de la locura?, opus cit., (1972), PP. 7-17.

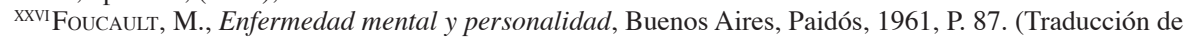
Emma Kestelboim). Edición original, FOUCAULT, M., Maladie mental y personnalité, París, Presses Universitaires de France, 1954.

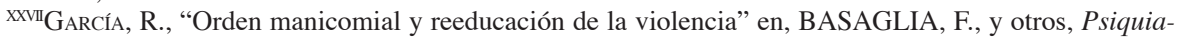
tría, antipsiquiatría y orden manicomial, Barcelona, Barral Editores, 1975, PP. 13-29. (Prólogo y selección de Ramón García).
} 
enfermedad mental, tanto en sus dimensiones psicológicas como en sus causas reales, se estudia como un fenómeno de la civilización en relación con el mundo y la realidad social. Probablemente la utilización del enfoque fenomenológico ${ }^{\mathrm{XVVIII}}$ determinó ciertas reticencias de Foucault a esta obra ${ }^{\text {XxIx. }}$, en cambio en Historia de la locura la conducta rara y desviada se plantea como un objeto artificial, construido a lo largo de la historia a partir de unas prácticas determinadas, por lo que su objetivación por parte de la medicina y la psiquiatría sería inadecuada. Es decir en la Historia de la locura el loco mantiene una forma peculiar de razón, necesaria para comprender la naturaleza del hombre y su realidad ${ }^{\mathrm{Xxx}}$.

El autor de ;Abajo la autoridad! Ciencia, manicomio y muerte no se reconoció en la etiqueta de la antipsiquatría ni le inquietó cómo nombrar a la psiquiatría crítica, más bien prefirió contarnos sus experiencias como médico. A partir de la imbricación entre el saber y el poder justificó su duro alegato contra la dominación y contra la autoridad en sus diferentes instituciones: la familia, la escuela, la universidad, el ejército, el manicomio, la iglesia, la cárcel y, en última instancia el Estado, que nos impone a las demás. Como consecuencia, en su lectura ácrata de los textos foucaultianos identificó al Estado, escrito con mayúscula, como responsable final del funcionamiento de todas las instituciones, y una vez localizado el monstruo se esforzó en destruirlo.

A finales de 1976 las publicaciones El Viejo Topo y Ajoblanco dejaron constancia en sus páginas de la moda antipsiquiátrica, estrenando sendas secciones de Antipsiquiatría. La revista ácrata facilitó a la locura la eventualidad de expresarse libremente, potenciando su faceta contestataria de manera análoga a como se hacía en Francia, desde 1969, en la revista Cuadernos para la locura. La presentación de Ajoblanco, en su sección Antipsiquiatría, no pudo ser más apremiante: es necesario, (en alusión a Foucault), que los locos tomen la palabra para potenciar el contacto directo, espontáneo y vitalista de todos aquellos que hayan tenido algún encuentro con la psiquiatría en calidad de pacientes mentales -neuróticos, esquizofrénicos, homosexuales, psicópatas, toxicómanos, etc., y que comuniquen sus experiencias y vivencias, al tiempo que expresen sus gritos de protesta ${ }^{X X X I}$. Por su parte, El Viejo Topo publicó varias entrevistas a los repre-

XXVIII Véase especialmente el enfoque fenomenológico sobre la imaginación de "Enfermedad mental y existencia" en, FOUCAULT, M., Enfermedad mental y personalidad, opus cit., (1961), y la "Introduction" en, BINWANGER, L., Le rêve et l'existence, París, Desclee de Brouwer, 1954, PP. 7-128.

xxix Foucault, M., Maladie mental et psychologie, París, Presses Universitaires de France (PUF), 1962, reimpresa en 1966. El texto es la reformulación de su primera obra de 1954, Enfermedad mental y personalidad, con profundos cambios en la segunda parte que concluye con una discusión sobre la teoría psicológica soviética. Sin embargo, no se publicó como una edición revisada, y con posterioridad su autor no permitió una nueva edición.

xxx Moreno, B., "La naturaleza de la locura según Michel Foucault. La historia de la locura como tesis", Clínica y Análisis Grupal, 1986, n 42, Año 10, Octubre-Diciembre, PP. 628-656.

xxxI “Sección Antipsiquiatría”, Ajoblanco, 1976, n 16, Noviembre, PP. 46-47, P. 46. 
ORIGINALES Y REVISIONES

sentantes de la psiquiatría crítica y una serie de fragmentos que nos remitían a las obras de Basaglia, Cooper, Gentis, Reich, el "Colectivo Socialista de Pacientes" (SPK) de Heidelberg, Deleuze, Guattari, Castel ${ }^{\mathrm{XXXI}}$, y por supuesto a Foucault, en concreto a su artículo "La casa de la locura" y al ensayo Enfermedad mental y personalidad. La finalidad de estas publicaciones consistió en aproximarnos a los contenidos centrales de la teoría y la práctica antipsiquiátricas para crear una conciencia colectiva sobre dicha problemática, ya que ésta no podía resolverse sólo a nivel científico sino que se exigía un debate público, cuya significación y naturaleza debían comprender los propios usuarios.

Por los autores aludidos deducimos cierta confusión en la supuesta moda antipsiquiátrica. En el caso de Foucault los textos citados se pueden ubicar, por su concepción de la enfermedad, como próximos a la antipsiquiatría, si tenemos en cuenta que no existió un bloque homogéneo ni una corriente con postulados teóricos compartidos y coherentes. En este sentido fue útil la división propuesta por los psiquiatras J. L. Fábregas Poveda y A. Calafat, quienes diferenciaron tres direcciones fundamentales dentro de la antipsiquiatría: la fenomenológicoexistencial en la que incluyen a Ronald Laing y Aarón Esterson, la político-social con Cooper, Basaglia, Deleuze, Guattari y el "Colectivo Socialista de Pacientes" (SPK), y la tercera, de carácter ético-sociológica, con Thomas Szasz a la cabe$\mathrm{Za}^{\mathrm{XXXIII}}$.

La respuesta a la participación popular, requerida por Ajoblanco y El Viejo Topo, no se hizo esperar. Se creó un "Colectivo de locos"Xxxiv que denunció su relación con la institución psiquiátrica por considerar a los locos como culpables de su enfermedad. Ante tanta cordura institucional, el colectivo reclamó el derecho a la locura que debía de asumir la sociedad y que ellos mismos, como afectados, pudieran encontrar sus propias soluciones. Más tarde se denominaron "Colectivo Crítico para la Salud Mental"Xxxv, cuyo miembro fundador fue Ramón García, integrándose en la "Red Internacional de Alternativa a la Psiquiatría", institución en la que destacó como uno de los inspiradores del "Réseau" europeo el sociólogo Robert Castel. De manera paralela coexistió el "Colectivo de Psiquiatrizados en Lucha"Xxxvi, organizado en torno al Hospital de día de Madrid, con una sección autónoma de servicio de psiquiatría clásica situada en

xxxII Para consultar los autores con sus respectivas obras véase, El Viejo Topo, "Sección Antipsiquiatría", 1977, nº 4, Enero, PP. 29-40.

xxxiII Calafat, A.; Fábregas Poveda, J. L., Política de la Psiquiatría, Barcelona, ZYX, 1975.

xxxiv "Por un colectivo de locos", Ajoblanco, 1977, n 21, Abril, P. 47.

xxxv Colectivo para la Salud Mental, "Hacia la salud mental. Desmixtificación de la antipsiquiatría", Ajoblanco, 1978, n 34, Junio, PP. 56-57.

XxxvI Colectivo "Psiquiatrizados en lucha", Ajoblanco, 1978, n 30, Febrero, PP. 46-47. También véase, "II Manifiesto del Colectivo de Psiquiatrizados en lucha”, El Viejo Topo, 1980, n 47, Agosto, PP. 72-73. 
la ciudad sanitaria "Francisco Franco". Probablemente el único lugar abierto a todo tipo de psiquiatría no-represiva, alternativa o antipsiquiátrica que funcionó de manera progresiva desde 1974, y que dirigieron los psiquiatras E. González Duro y M-P. Marina. La experiencia de esta auténtica comunidad terapéutica fue inédita en España no sólo por su régimen abierto, sino porque en ella convivieron hombres y mujeres ${ }^{\mathrm{XXXVII}}$.

Desde sus inicios estos grupos de psiquiatrizados estuvieron en contacto con los diferentes "Réseaux"XxxvIII, incorporándose al celebrado en Trieste en 1977. En éste se decidió redactar el texto constitutivo del Réseau, cuyas pretensiones fundamentales fueron: la abolición de todas las formas de encierro psiquiátrico, la crítica al sector médico por su práctica como relevo tecnocrático al asilo, el apoyo incondicionado a los grupos que evitasen la psiquiatrización, y la denuncia de técnicas de tratamiento como la psicofarmacología, el electroshock, la psicocirugía o el coma insulínico. Cercano al "Réseau" europeo se desarrollaron unas "Jornadas de Psiquiatría Alternativa"Xxxix, organizadas por un comité de estudiantes de Medicina y Psicología, con la participación, entre otros, de José Luis Fábregas, Enrique González Duro y Manuel González de Chávez. En estas Jornadas, celebradas en Asturias, se reivindicó un cambio radical en la psiquiatría para que no fuese represiva ni segregadora, sino liberadora, integradora y comunitaria. La medicina había elaborado una teoría y una praxis que justificó científicamente la represión de la locura, reconvertida después en enfermedad mental y desconectada por completo de las circunstancias en que se producía. De este modo el manicomio encarnó la respuesta institucional del Estado moderno a la necesidad existente de recluir y controlar a un número creciente de personas marginales, económicamente inútiles, socialmente irrelevantes y políticamente ineficaces, quienes por su conducta supuestamente anormal e irracional podían perturbar y alarmar al resto de los ciudadanos, incluidos normalmente en el orden social $^{\mathrm{XL}}$.

Podemos constatar como la Historia de la locura ejerció una influencia decisiva en psiquiatras como Julián Espinosa, González Duro, Carmen Sáez Buenaventura, José L. Fábregas y González de Chávez. Para estos especialistas, a partir de la Ilustración, con la reforma de las cárceles y de las instituciones de

xxxiI GonzÁlez Duro, E.; Marina, M-P., "Hospital de día de Madrid: autocrítica de una alternativa", Ajoblanco, 1979, n 43, Marzo, PP. 58-61. El Hospital General aludido dependía, en esos años, de la Diputación Provincial de Madrid.

xxxvIII Los “Réseaux" se celebraron en Bruselas (1975), París (1976), Trieste (1977), y Ginebra (1978).

xxxix En las "Jornadas de Psiquiatría Alternativa” participaron, entre otros, los psiquiatras, E. González Duro, M. González de Chávez, Enrique Mora, J. L. Fábregas, José García, Ernesto Venturini, colaborador de Basaglia, y Guillermo Rendueles. Jornadas organizadas en Oviedo del 7 al 10 de Diciembre de 1978. Véase, El Viejo Topo, "Jornadas de psiquiatría alternativa", $\mathrm{n}^{\circ}$ 27, Diciembre, 1978, P. 74.

XL González Duro, E., "Hacia una nueva dialéctica sobre la locura”, Ajoblanco, 1978, Marzo, PP. 6-8. 
ORIGINALES Y REVISIONES

corrección y asilos, se erigió la necesidad de levantar lugares especiales para recluir a los dementes y deshacerse de personajes tan molestos. Con posterioridad el médico tomó posesión de las instituciones destinadas a la custodia del loco, garantizando técnicamente el encierro y apropiándose de las funciones de árbitro para decidir quién se encontraba fuera o dentro de la norma. La psiquiatría se alió al estamento jurídico iniciando de esta forma uno de sus roles característicos hasta la actualidad, la figura del médico-legal. No nació como fruto del desarrollo de una cierta parcela del saber médico como ocurrió con otras especialidades, sino que apareció tras hacer médico un problema primariamente social, sin contar con un cuerpo de doctrina coherente que justificase su presencia en las instituciones. Con el paso de los años fue ensanchando su radio de acción, haciendo suyos un sinfín de problemas sociales: desde el alcoholismo a la homosexualidad, desde la inadaptación escolar o laboral al inconformismo político. La ciencia psiquiátrica optó por el camino más recto y seguro, el que le proporcionó éxito social con la clásica separación de los enfermos en dos "especies" distintas: los curables y los incurables. Esta segregación arbitraria permanece de una u otra forma invariable, con la paradoja actual de que oficialmente la locura es curable, aunque la mayoría de los locos no se curan ${ }^{\text {XLI }}$.

Lejos de presentar a la psiquiatría institucional como una ciencia médica, neutral y aséptica, González Duro desveló sus dudosas intenciones dirigidas tanto a su objeto, los llamados enfermos mentales, como a sus objetivos en la praxis social. El tratamiento psiquiátrico supuso un pretexto médico para encubrir una función ético-política de control de ciertos desviados sociales, cuyo destino ejercitó en pro de los poderes establecidos: realmente, la psiquiatría actúa como una estructura de poder-saber, que define, conceptualiza, clasifica, controla y corrige las locuras de gentes débiles y marginadas, de acuerdo con los intereses y valores de una sociedad <normalizada $>y<$ normalizante $>$, valores que corresponden a los de la ideología dominante ${ }^{X L I I}$. Carmen Sáez Buenaventura, por su parte, extendió su denuncia de la práctica psiquiátrica conservada dentro de los ritos del asilo, recubierta por los mitos del positivismo y concebida mayoritariamente como una táctica moral patriarcal, ya que no tenemos conocimiento -hasta los primeros años del siglo XX-de la existencia de ninguna mujer psiquiatra en las instituciones, al menos en Europa ${ }^{\mathrm{XLIII}}$.

A finales de 1979 se celebró en Madrid el "XV Congreso de la Asociación

XLI EsPinOSA, J., "El nacimiento de los manicomios" en, BASAGLIA, F., y otros, Psiquiatría, antipsiquiatría y orden manicomial, opus cit., (1975), PP. 33-51.

22.

xLI GonZÁlez Duro, E., "El aparato psiquiátrico", El Viejo Topo, Extra nº 7, 1979, Septiembre, PP. 22-27, P.

xLIII SÁez Buenaventura, C, "Las mujer en la profesión psiquiátrica” en, BUGALLO, M., y otros, Conflictos y lucha psiquiátrica en España, Madrid, Dédalo Ediciones, 1978, PP. 147-166. 
Española de Neuropsiquiatría", que reunió a una cincuentena de profesionales de la salud mental. El evento, como instrumento de información, reflexión y debate, sirvió en la práctica para ayudar a todos los que estaban implicados en la transformación de la asistencia psiquiátrica. Cabe destacar la ponencia del psiquiatra González de Chávez, coordinador del Congreso, recomendando a sus colegas la lectura y conocimiento de los textos foucaultianos para el buen quehacer de los profesionales de la salud mental: la obra de Michel Foucault en su conjunto y los magníficos trabajos $<$ Historia de la locura en la época clásica $>,<$ Nacimiento de la clínica $>,<$ Vigilar y castigar $>$, o la $<$ Historia de la sexualidad $>$ merecen más atención de los profesionales de la salud mental progresistas (...) FOUCAULT (sic) es uno de los más inteligentes e interesantes pensadores de nuestro tiempo y ha dedicado buena parte de sus esfuerzos a desmontar la lógica institucional de la sociedad actual con agudos análisis basados en un buen conocimiento de los tres últimos siglos, periodo histórico que desde su perspectiva parece serle suficiente ${ }^{X L I V}$.

Por tanto, el psiquiatra citó dos textos cercanos aunque diferentes entre sí a la ciencia médica, como son la Historia de la locura y el Nacimiento de la clínica. Y dos obras, Vigilar y castigar y La Voluntad de saber, relativamente recientes en su publicación a la celebración del Congreso, lo cual demuestra el interés que suscitó en González de Chávez el pensamiento de Foucault. Esta observación contrasta con la ignorancia o con la indiferencia de los médicos allí reunidos, puesto que en las restantes conferencias y comunicaciones recogidas en las setecientas páginas de las Actas del Congreso, posteriormente publicado, no existe ninguna referencia al filósofo de Poitiers. Otro de los congresistas reflexionó sobre la absoluta miseria de la psiquiatría oficial durante el franquismo, en concreto por su negativa a cualquier investigación, análisis o debate que fuese más allá de la pobre especulación desenraizada de la realidad. Según Manuel Desviat lo único que había cambiado era el formalismo a nivel académico: $s i$ ayer cualquier disidencia era denunciada como comunista, -como política-, hoy día el anatema es antipsiquiatría, es decir, izquierdismo radical, anarquizante, extraparlamentario, sospechosos para el orden social ${ }^{X L V}$.

Sin duda que el término antipsiquiatría, que hacía tiempo que ni el mismo Cooper lo reconocía, sirvió de estigma a buena parte de aquellos que pretendieron la transformación de la asistencia psiquiátrica en España. Es significativo que

xliv González De Chávez, M., "Historia de los cambios asistenciales y sus contextos sociales".en, GONZÁLEZ DE CHÁVEZ, M. (coord.), La transformación de la asistencia psiquiátrica, Madrid, Mayoría, 1980, PP. 13-106, P. 40.

xLV Desviat, M., "Las herramientas del cambio psiquiátrico: entre la integración y la ruptura”.en, GONZÁLEZ DE CHÁVEZ, M., La transformación de la asistencia psiquiátrica, opus cit., (1980), PP. 630-704. 
ORIGINALES Y REVISIONES

el sociólogo Fernando Álvarez-Uría, tras la ruidosa moda de la antipsiquiatría, lamentara las escasas transformaciones de la psiquiatría en el campo social, sobre todo porque la ciencia médica jugó un papel decisivo en la generalización del control social de las poblaciones, advirtiendo que la psiquiatría era demasiado seria para dejarla únicamente en manos de los psiquiatras ${ }^{X L V I}$.

En esta acogida extraacadémica del pensamiento de Michel Foucault podemos constatar las diferentes condiciones sociales de los intérpretes y de los lectores, profanos y académicos, como también los campos de recepción de los textos, es decir, campo intelectual y campo político. En la coexistencia de dichos públicos e interpretaciones y de sus lecturas y necesidades es donde se aprecia una mayor fecundidad de la "caja de herramientas" foucaultiana, a disposición de los movimientos sociales que hicieron un uso político y reivindicativo de su obra, poniendo en liza aspectos que habían sido anteriormente marginados por la tradición filosófica académica, como en este caso los manicomios y los hospitales ${ }^{\mathrm{XLVII}}$. 
ORIGINALES Y REVISIONES

\section{BIBLIOGRAFIA:}

(1) Álvarez-Uría, F., "De la policía de la pobreza a las cárceles del alma”, El Basilisco, 1979, nº 8, Julio-Diciembre, PP. 64-71.

(2) Basaglia, F. Y Otros, ¿Psiquiatría o ideología de la locura?, Barcelona, Anagrama, 1972. (Selección, revisión y notas de Ramón García).

(3) Basaglia, F.; Basaglia, F. (compiladores), La institución negada, Barcelona, Barral Editores, 1972. (Traducción de Jaime Pomar).

(4) Basaglia, F., Y Otros, Psiquiatría, antipsiquiatría y orden manicomial, Barcelona, Barral Editores, 1975. (Prólogo y selección de Ramón García).

(5) Basaglia Y Otros, Los crímenes de la paz, Méjico, Siglo XXI, 1977. (Traducción de Carmen Valcarce).

(6) Calafat, A.; Fábregas Poveda, J. L., Política de la Psiquiatría, Barcelona, ZYX, 1975.

(7) Cohn-Bendit, D., “Anniversaire: Cohn-Bendit raconte Mai 68”, Le Nouvel Observateur, 1975, $\mathrm{n}^{\circ}$ 547, 5 Agosto-1 Mayo, PP. 71-106.

(8) COLECTIVO DE LOCOS, Ajoblanco, 1977, n 21, Abril, P. 47.

(9) COLECTIVO "Psiquiatrizados en lucha", Ajoblanco, 1978, n 30, Febrero, PP. 46-47.

(10) COLECTIVO PARA LA SALUD MENTAL: "Hacia la salud mental. Desmixtificación de la antipsiquiatría", Ajoblanco, 1978, n 34, Junio, PP. 56-57.

(11) COLECTIVO "Psiquiatrizados en lucha" (II Manifiesto), El Viejo Topo, 1980, n 47, Agosto PP. 72-73.

(12) CoOper, D., Psiquiatría y Antipsiquiatría, Buenos Aires, Paidós, 1978, $4^{\text {a }}$ edición. (Traducción de Jorge Piatigorsky).

(13) Deleuze, G.; Guattari, F., El Anti Edipo. Capitalismo y esquizofrenia, Barcelona, Paidós, 1985. (Traducción de Francisco Monge).

(14) Desviat, M., "Las herramientas del cambio psiquiátrico: entre la integración y la ruptura".en,

(15) Espinosa, J., "El nacimiento de los manicomios" en, BASAGLIA, F., y otros, Psiquiatría, antipsiquiatría y orden manicomial, Barcelona, Barral Editores, 1975, PP. 33-51.

(16) EzINE, J. L., "Sur la sellette: Michel Foucault", (Entrevista con Michel Foucault: "Acerca del banquillo"), Les Nouvelles Littéraires, 1975, n² 2477, 17-23 de Marzo, P. 3.

(17) Fábregas, J. L.; Mora, E.; RoIG, A., "Por una psiquiatría alternativa", El Viejo Topo, $1977, \mathrm{n}^{\circ} 15$, PP. $18-23$

(18) Foucault, M., "Introduction" en, BINWANGER, L., Le rêve et l'existence, París, Desclee de Brouwer, 1954, PP. 7-128.

(19) Foucault, M., Enfermedad mental y personalidad, Buenos Aires, Paidós, 1961. (Traducción de Emma Kestelboim).

(20) Foucault, M., Maladie mental et psychologie, París, Presses Universitaires de France (PUF), 1962, reimpresa en 1966.

(21) Foucault, M., Historia de la locura en la época clásica Méjico, Fondo de Cultura Económica, 1976. (Traducción de Juan José Utrilla, $2^{a}$ edición de FCE).

(22) Foucault, M., La vida de los hombres infames. Ensayos sobre desviación y dominación, Madrid, La Piqueta, 1990. (Traducción de Julia Varela y Fernando Álvarez-Uría).

(23) Foucault, M., Hay que defender la sociedad, Buenos Aires, Almagesto, 1992. (Traducción de Jorge Fernández Vega). 
(24) Foucault, M., "El Antiedipo: una introducción a la vida no fascista”, Archipiélago. Cuadernos de crítica de la cultura, 1994, n 17, Octubre-Diciembre, PP. 88-91.

(25) Foucault, M., El poder psiquiátrico, Madrid, Akal, 2005.

(26) Foucault, M., "La casa de la locura" en, BASAGLIA y otros, Los crímenes de la paz, Méjico, Siglo XXI, 1977, PP. 135-150.

(27) García, R., "Una experiencia frente a la ciencia" en, BASAGLIA, F. y otros, ¿Psiquiatría o ideología de la locura?, Barcelona, Anagrama, 1972, PP. 7-17.

(28) García, R., "Orden manicomial y reeducación de la violencia" en, BASAGLIA, F., y otros, Psiquiatría, antipsiquiatría y orden manicomial, Barcelona, Barral Editores, 1975, PP. 13-29.

(29) García, R., "Los conflictos psiquiátricos en España: de la renuncia del manicomio a la ruptura con la norma institucional", El Viejo Topo, 1977, n 4, Enero, PP. 37-39.

(30) García, R., jAbajo la autoridad! Ciencia, manicomio y muerte, Barcelona, Anagrama, 1979.

(31) García, R.; Serós, A.; Torrent, L., "Una experiencia frente a la ciencia" (Prólogo) en, BASAGLIA, F.; BASAGLIA, F. (compiladores): La institución negada, Barcelona, Barral Editores, 1972, PP. 7-17.

(32) Goffman, E., Internados. Ensayos sobre la situación social de los enfermos mentales, Madrid, Martínez de Murguía, 1970. (Traducción de María Antonia Oyuela de Grant).

(33) GonzÁlez De Chávez, M. (coord.), La transformación de la asistencia psiquiátrica, Madrid, Mayoría, 1980.

(34) González Duro, E., "Hacia una nueva dialéctica sobre la locura", Ajoblanco, "Extra Antipsiquiatría”, 1978, Marzo, PP. 6-8.

(35) GonzÁlez Duro, E., "El aparato psiquiátrico", El Viejo Topo, 1979, Extra nº 7, Septiembre, PP. 22-27.

(36) González Duro, E.; Marina, M-P., "Hospital de día de Madrid: autocrítica de una alternativa", Ajoblanco, 1979, no 43, Marzo, PP. 58-61.

(37) Moreno, B., "La naturaleza de la locura según Michel Foucault. La historia de la locura como tesis", Clínica y Análisis Grupal, 1986, n 42, Año 10, Octubre-Diciembre, PP. 628-656.

(38) Morey, M., "Taller de títeres: de instintos e instituciones", El Viejo Topo, 1977, no 6, Marzo, PP. 43-44.

(39) Morey, M., "Introducción a Michel Foucault" en, Sexo, Poder, Verdad. Conversaciones con Michel Foucault, Barcelona, Materiales, 1978, PP. 9-65.

(49) RiBAs, J., Los 70 a destajo. Ajoblanco y libertad, Barcelona, RBA, 2007.

(59) Sáez Buenaventura, C, "Las mujer en la profesión psiquiátrica" en, BUGALLO, M., y otros, Conflictos y lucha psiquiátrica en España, Madrid, Dédalo Ediciones, 1978, PP. 147-166.

(60) “SECCIÓN ANTIPSIQUIATRÍA", Ajoblanco, 1976, n 16, Noviembre, PP. 46-47

(61) “SECCIÓN ANTIPSIQUIATRÍA”, El Viejo Topo, 1977, nº 4, Enero, PP. 29-40.

(62) Soler, S.; Arqués, R., "Entrevista a Michel Foucault", Ajoblanco, 1978, n 31, Marzo, PP. 13-15

(63) Varela, J.; Álvarez-Uría, F., "Psicoanálisis y control social”, Negaciones, 1976, nº 2 , Diciembre, PP. 151-163.

(64) Vicens, A., "Filosofía y desobediencia" (Entrevista a François Châtelet), El Viejo Topo, 1977, nº 10, Julio, PP. 39-43. 
ORIGINALES Y REVISIONES

* VALENTín GALVÁN. Calle Rafael de la Viesca, n 10 , 4. C. P.: 11003. CÁDIZ. Licenciado en Filosofía y Antropología. Doctor en Filosofía y Letras. Universidad de Cádiz. Tfno.: 956224141

Correspondencia: Correo electrónico: guiomar40@hotmail.com

** Recibido: 8/05/2009 